\title{
NITROGÊNIO NO CRESCIMENTO DE PLANTAS DE Physalis angulata L. EM CULTIVO HIDROPÔNICO
}

\author{
Romeu da Silva Leite ${ }^{1}$; Lenaldo Muniz de Oliveira ${ }^{2}$; Marilza Neves do \\ Nascimento $^{3}$; Tamara Torres Tanan ${ }^{4}$; Vanessa Chaves da França ${ }^{5}$ \\ 1.Bolsista PIBIC/CNPq, Graduando em Agronomia, Universidade Estadual de Feira de Santana, e-mail: \\ leiteromeu@hotmail.com \\ 2. Orientador, Departamento de Ciências Biológicas, Universidade Estadual de Feira de Santana, e-mail: \\ lenaldo.uefs@gmail.com \\ 3. Participante do projeto, Departamento de Ciências Biológicas, Universidade Estadual de Feira de Santana, e-mail: \\ marilzaagro@ hotmail.com \\ 4. Participante do projeto, Departamento de Ciências Biológicas, Universidade Estadual de Feira de Santana, e-mail: \\ tanara.tanan@yahoo.com.br \\ 5. Participante do projeto, Departamento de Ciências Biológicas, Universidade Estadual de Feira de Santana, e-mail: \\ vanessafranca2011@ hotmail.com
}

PALAVRAS-CHAVE: camapú, adubação nitrogenada, hidroponia.

\section{INTRODUÇÃO}

O camapú (Physalis angulata), pertencente à família Solanaceae, é uma espécie de ocorrência natural em todo o território brasileiro que vem despertando interesse dos consumidores e produtores devido ao valor nutracêutico e potencial para a fruticultura. Contudo, as técnicas do seu cultivo são incipientes, sendo utilizadas as recomendações para a cultura do tomate. Um fator relevante para o aumento da produção da espécie é o emprego da adubação, sobretudo a nitrogenada. No entanto, as plantas utilizam menos da metade dos fertilizantes aplicados, e o restante pode ser lixiviado para os lençóis subterrâneos, tornar-se fixado ao solo ou contribuir para a poluição do ar (LACERDA et al., 2007).

Dentre os elementos essenciais para as plantas completarem seu desenvolvimento destaca-se o nitrogênio, um dos nutrientes mais absorvidos pelas plantas, com efeito direto na distribuição de fotoassimilados entre a parte vegetativa e reprodutiva, promovendo modificações na fisiologia e morfologia da planta, estando relacionada com a fotossíntese, ampliação do sistema radicular, absorção iônica de nutrientes e desenvolvimento celular (QUEIROGA et al., 2007). O excesso ou deficiência deste nutriente é prejudicial à planta, afetando seu crescimento e produção podendo resultar em perdas significativas (ALVARENGA, 2004). Diante do exposto, o presente trabalho objetivou avaliar o crescimento e produção de plantas de $P$. angulata em cultivo hidropônico sobre diferentes doses de nitrogênio.

\section{METODOLOGIA}

O experimento foi realizado na Unidade Experimental Horto Florestal (UNEHF) da Universidade Estadual de Feira de Santana (UEFS), localizada no município de Feira

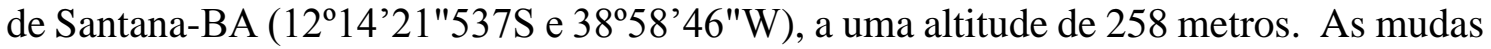
foram produzidas a partir de sementes obtidas de plantas cultivadas na UNEHF/UEFS, semeadas em substrato comercial (Plantmax ${ }^{\circledR}$ ) e transplantadas para o sistema hidropônico aos 15 dias após a emergência.

O experimento constituiu-se de 60 vasos de polipropileno com capacidade para 7 litros, em 6 litros de solução nutritiva. A solução nutritiva foi aerada por quinze minutos a cada três horas durante a condução do experimento, através de compressor $(250 \mathrm{~W}$, com capacidade de deslocamento de ar de $100 \mathrm{~L} / \mathrm{min}$.). O delineamento utilizado foi 
inteiramente casualizado com cinco tratamento, constituídos pelas doses de $\mathrm{N} 0,56,112$, 168 e $224 \mathrm{mg} . \mathrm{L}^{-1}$ e doze repetições por tratamento, constituída de um vaso com uma planta cada repetição. Utilizou-se a solução nutritiva de Sarruge (1975), modificada para suprir cada dose de nitrogênio.

As avaliações do crescimento foram realizadas aos 40 DAT, utilizando-se quatro plantas por tratamento definidas de forma aleatória. Foram avaliados os seguintes parâmetros: altura da planta, expresso em centímetros, utilizando-se trena graduada; diâmetro do caule, obtidos com o auxílio de paquímetro digital com 0,01 de precisão e produção de frutos, determinada a partir da pesagem em balança de precisão. A área foliar foi mensurada pelo método dos discos foliares, utilizando um furador com área conhecida, retirando-se 9 discos foliares por planta. Os discos foram acondicionados em sacos de papel e colocados em estufa de circulação forçada de ar a $60{ }^{\circ} \mathrm{C}$ por 72 horas. Posteriormente, foram pesados separadamente em balança analítica. Para determinação da área foliar utilizou-se a seguinte equação: Área foliar= $(($ Massa seca da folha $(\mathrm{g})+$ Massa seca dos discos (g)) /Massa seca dos discos (g)) x área do discos.

A produtividade dos frutos estimada por hectare foi calculada a partir da equação: produtividade $=$ produção por planta $(\mathrm{t}) \times 10.000 \mathrm{~m}^{2} /$ área ocupada por planta. Em seguida, o material vegetal foi acondicionado em sacos de papel e transferido para estufa com circulação forçada de ar, para determinação da massa seca da parte aérea (MSPA).

Os dados obtidos foram submetidos à análise de variância e de regressão, sendo ajustadas as equações das características avaliadas, como variáveis dependentes das concentrações de nitrogênio. As análises estatísticas foram realizadas aplicando-se o software estatístico Sisvar 4.1 (FERREIRA, 2008).

\section{RESULTADOS E DISCUSSÃO}

Para matéria seca da parte aérea (MSPA), a equação obtida apresentou $\mathrm{R}^{2}$ de 0,99 , mostrando um aumento dessa variável com o aumento da concentração de $\mathrm{N}$ na solução nutritiva (Figura 1A). O aumento da concentração de $\mathrm{N}$ na solução nutritiva teve efeito na área foliar das plantas, observando-se uma tendência linear $\left(\mathrm{r}^{2}=0,98\right)$. No tratamento controle, sem o fornecimento de nitrogênio, a área foliar foi de $2,41 \mathrm{~cm}^{2}$, já na maior dosagem (224 mg. $\mathrm{L}^{-1}$ de N) o valor obtido foi 5.332,11 $\mathrm{cm}^{2}$ (Figura 1B). Sabe-se que o aumento da área foliar ou do dossel fotossintético, tem como objetivo promover melhor aproveitamento da energia solar relacionada com a geração de fotoassimilados e consequentemente com o aumento da massa seca da parte aérea, o que foi observado nesse trabalho (PURQUERIO et al., 2007).

Vale ressaltar que o cultivo na hidroponia antecipou as fases fenológicas da espécie $P$. angulata e que aos 40 DAT a planta já apresentava frutos maduros, enquanto que em um trabalho realizado por TANAN (2015) na mesma época e em campo, aos 44 DAT, observou-se apenas a presença de botões florais. Como a planta nessa fase já está produzindo frutos não é interessante que aumente a parte vegetativa, e sim, que o investimento seja direcionado a produção de frutos.

A altura da planta e o diâmetro do caule foram influenciados pelos tratamentos utilizados, sendo a relação mais bem ajustada pelo modelo quadrático, apresentando $\mathrm{R}^{2}$ de 0,91 e 0,96 , respectivamente. Para a altura houve aumento até a dose de 166,3 mg. $\mathrm{L}^{-1}$ de N, com média de 93,9cm (Figura 1C). O diâmetro do caule mostrou comportamento similar, com máximo valor $\left(22,3 \mathrm{~mm}\right.$ ) na dose estimada de $172,0 \mathrm{mg} . \mathrm{L}^{-1}$ de $\mathrm{N}$ (Figura 1D). A redução do tamanho das plantas, decorrente da aplicação de doses maiores indica que essa dose pode ter contribuído para o desequilíbrio entre outros elementos, reduzindo o seu crescimento (SOUZA \& SORATTO, 2006). 
A produção de frutos apresentou resposta quadrática $\left(\mathrm{R}^{2}\right.$ de 0,95$)$, com a maior massa dos frutos (48,4 g.planta ${ }^{-1}$ ) na dose estimada de 213,8 mg. $\mathrm{L}^{-1}$ de N (Figura 1E). A dose estimada de $211,9 \mathrm{mg} . \mathrm{L}^{-1}$ de $\mathrm{N}$ proporcionou maior ganho de produtividade, apresentando 2,99 t.ha ${ }^{-1}$ (Figura 1F). O aumento na produtividade dos frutos é uma característica desejável, tratando-se de uma espécie com grande potencial de cultivo e aproveitamento dos frutos para o consumo in natura e para industrialização.
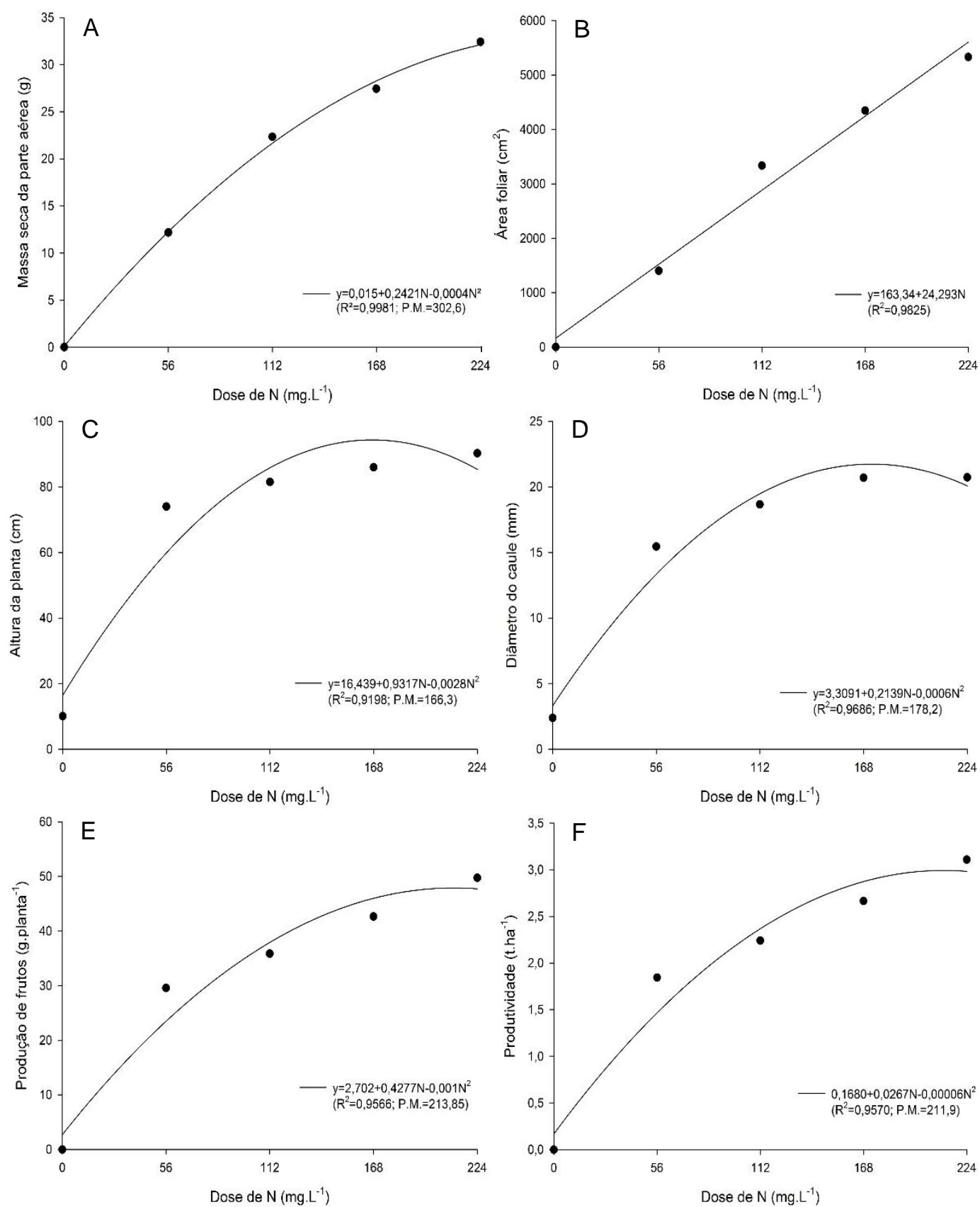

Figura 1. Massa seca da parte aérea (A), área foliar (B), altura da planta (C), diâmetro do caule (D), produção de frutos (E) e produtividade (F) das plantas de Physalis angulata submetidas a diferentes concentrações de nitrogênio na solução nutritiva. 


\section{CONCLUSÃO}

A espécie Physalis angulata adapta-se bem ao cultivo hidropônico, sendo mais uma alternativa para o cultivo da espécie. Maiores ganhos em produtividade podem ser alcançados quando fornecido a dose estimada de 211,9 mg. $\mathrm{L}^{-1}$ de $\mathrm{N}$ em solução nutritiva completa.

\section{REFERÊNCIAS}

LACERDA, C. F.; FILHO, J. E.; PINHEIRO C.B. Fisiologia Vegetal. Universidade Federal do Ceará. Fortaleza, 2007. Disponível em < http://www.fisiologiavegetal.ufc.br/apostila.htm> Acesso em: 10 de setembro 2016.

FERREIRA, D. F. SISVAR: Um programa para analises e ensino de estatística. Revista Científica Symposium, v. 6, p. 36-41, 2008.

ALVAREnGA, M. Tomate: Produção em campo, em casa de vegetação e em hidroponia. Lavras: UFLA, 2004.

SARRUGE, J.R. Soluções nutritivas. Summa Phytopathologica, v.1, n.3, p.231-233, 1975.

SOUZA, E. F. C.; SORATTO, R. P. Efeito de fontes e doses de nitrogênio em cobertura, no milho safrinha, em plantio direto. Revista Brasileira de Milho e Sorgo, v.5, n.3, p.395-405, 2006.

PURQUERIO, L. F. V. et al. Efeito da adubação nitrogenada de cobertura e do espaçamento sobre a produção de rúcula. Horticultura Brasileira, v. 25, n. 3, p. 464470, 2007.

QUEIROGA, R. C. F. et al. Influência de doses de nitrogênio na produtividade e qualidade do melão Cantalupensis sob ambiente protegido. Horticultura Brasileira, v. 25 n. 4, 2007. 